JURNAL ILMU KESEHATAN BHAKTI HUSADA:

HEALTH SCIENCES JOURNAL, VOL. 11 No. 02, DESEMBER 2020

DOI: $10.34305 / j i k b h . v 11 i 2.169$
Ciptaan disebarluaskan di bawah

Lisensi Creative Commons

Atribusi-NonKomersial-

BerbagiSerupa 4.0 Internasional.

\title{
HUBUNGAN SIKAP TENTANG ALAT KONTRASEPSI PRIA DENGAN PARTISIPASI SUAMI MENGGUNAKAN ALAT KONTRASEPSI DI KELURAHAN KEBONBARU KOTA CIREBON
}

\author{
Maesaroh Maesaroh \\ Politeknik Kesehatan Bhakti Pertiwi Husada \\ maesarohnayla77@gmail.com
}

\begin{abstract}
Abstrak
Negara berkembang mempunyai berbagai jenis permasalahan yang dihadapi, salah satunya adalah masalah tingginya laju pertumbuhan penduduk, termasuk di dalamnya adalah Negara Indonesia. Pemerintah melalui program keluarga berencana (KB) berupaya melakukan penanggulangan laju pertumbuhan penduduk ini.Pada umumnya akseptor KB lebih banyak berasal dari kaum wanita, dibandingkan pria. Pasangan, dalam hal ini suami memiliki kewajiban yang sama untuk ikut berpartisipasi dalam melaksanakan program KB yang telah digalakan oleh pemerintah. Penelitian ini bertujuan untuk mengetahui hubungan sikap tentang alat kontrasepsi pria dengan partisipasi suami. Penelitian ini menggunakan metode penelitian analitik dengan pendekatan cross sectional, dengan jumlah populasi 1.022 jiwa, dan jumlah sampel 88 orang. Analisis dilakukan uji statistik chi-kuadrat. Hasil penelitian menunjukkan adanya hubungan sikap tentang kontrasepsi pria dengan partisipasi suami dalam menggunakan alat kontrasepsi di Kelurahan Kebonbaru Kota Cirebon dengan nilai $p$ value sebesar 0,001 lebih kecil dari nilai alpha 0,05. Diharapkan bagi pria usia subur dapat meningkatkan pengetahuan melalui informasi secara langsung dari petugas kesehatan atau media sosial sehingga dapat meningkatkan pengetahuan seputar alat kontrasepsi agar suami dapat ikut serta berpartisipasi dalam penggunaan alat kontrasepsi.
\end{abstract}

Kata Kunci: sikap, alat kontrasepsi, partisipasi suami

Pendahuluan

Negara berkembang mempunyai berbagai jenis permasalahan yang dihadapi, salah satunya adalah masalah tingginya laju pertumbuhan penduduk, termasuk di dalamnya adalah Negara Indonesia (Depkes, 2014). Pada tahun 2017 jumlah penduduk 
JURNAL ILMU KESEHATAN BHAKTI HUSADA:

HeAlth SCIENCES JOURNAL, Vol. 11 No. 02, DeSEMBER 2020 DOI: $10.34305 / j i k b h . v 11 i 2.169$

Indonesia sebanyak 261.890,9 juta jiwa jumlah penduduk tersebut terdiri dari 133,17 juta jiwa pria dan 131,88 juta jiwa wanita (BPS, 2018). Di antara negara ASEAN, Indonesia menjadi negara peringkat 5 dengan angka fertilitas atau Total Fertility Rate (TFR) 2,4. Angka ini berada diatas ratarata TFR negara ASEAN yaitu 2,3 (World Population Data Sheet, 2019).

Dalam upaya meningkatkan kesejahteraan, pemerintah telah berupaya mengatasi masalah laju pertumbuhan penduduk ini melalui berbagai bidang, salah satunya melalui program Keluarga Berencana $(\mathrm{KB})$. Program KB ini adalah upaya peningkatan peran serta masyarakat serta kepeduliannya melalui pendewasaan usia perkawinan, pengaturan jarak kelahiran, pembinaan ketahanan keluarga, serta termasuk di dalamnya peningkatan kesejahteraan keluarga kecil, bahagia dan sejahtera (Depkes, 2014).

Dalam upaya penanggulangan laju pertumbuhan penduduk, program ini dinilai efektif, serta memberikan keuntungan dari segi ekonomi pada pasangan suami istri, keluarga dan masyarakat. Selain dari segi ekonomi, pasangan suami istri juga harus mempunyai pengetahuan yang cukup baik dalam memilih kontrasepsi apa yang akan digunakan sehingga pengaturan jarak
Ciptaan disebarluaskan di bawah

Lisensi Creative Commons Atribusi-NonKomersialBerbagiSerupa 4.0 Internasional.

kehamilan yang diinginkan dapat diatur sedemikian rupa. Sehingga dalam meningkatkan status kesehatan dan kelangsungan hidup ibu, bayi dan anak program KB ini menjadi salah satu program pokok yang diusung pemerintah (Purwoastuti, 2014).

Berdasarkan data BKKBN jumlah peserta KB aktif di Indonesia tahun 2017 sebesar 23.606.218 juta jiwa, diantaranya peserta pengguna kondom 1,22 \% dan peserta MOP 0,53 \% (Kemenkes RI, 2018). Data yang diperoleh dari Dinas Pengendalian Penduduk dan Keluarga Berencana (DPPKB) Kota Cirebon Juni tahun 2019 jumlah Pasangan Usia Subur (PUS) yaitu 41.720 jiwa sedangkan jumlah pengguna KB aktif Metode Operasi Pria (MOP) $(0,27 \%)$, Metode Operasi Wanita (MOW) (21,96\%), Alat Kontrasepsi Dalam Rahim (AKDR) (34,03\%), Implan (12,89\%), Kondom (4,46\%) Pil (30,48\%), Suntik (159,12\%) (DPPKB, 2019). Data tersebut menunjukan bahwa kontrasepsi suntik dan pil merupakan alat kontrasepsi yang paling banyak diminati, sedangkan jenis kontrasepsi yang paling sedikit digunakan adalah MOP. Hal ini menunjukan angka partisipasi pria atau suami dalam penggunaan alat kontrasepsi di Indonesia masih sangat rendah. 
JURNAL ILMU KESEHATAN BHAKTI HUSADA:

HeAlth SCIENCES JOURNAL, Vol. 11 No. 02, DeSEMBER 2020 DOI: $10.34305 / j i k b h . v 11 i 2.169$

Umumnya akseptor KB lebih banyak berasal dari kaum wanita, dibandingkan dengan laki-laki. Sejatinya kaum laki-laki pun memiliki kewajiban untuk ikut menyukseskan program ini. Salah satu upaya untuk meningkatkan partisipasi suami dalam program KB ini adalah dengan mendorong keaktifan pria/suami dalam memutuskan menggunakan alat kontrasepsi yang dipakai baik menggunakan kondom atau melalui MOP/vasektomi (Ika, 2009)

Kurangnya

partisipasi pasangan/suami pada kontrasepsi disebabkan oleh lingkungan sosial budaya yang tidak mendukung, ditambah lagi tidak adanya dukungan dari pihak keluarga. Lingkungan sosial budaya menganggap bahwa penggunaan alat kontrasepsi adalah mutlak kewajiban wanita, serta adanya anggapan dimasyarakat bahwa akan berkurangnya kejantanan laki-laki jika menggunakan alat kontrasepsi (Novianti, 2014). Demikian juga menurut (Tourisia, dkk, 2015) yang menjelaskan bahwa banyaknya faktor penyebab rendahnya partisipasi pria dalam KB diantaranya pengetahuan. Terbatasnya pengetahuan lakilaki terhadap informasi dan Pelayanan KB, sikap serta faktor lingkungan dan akses terhadap pelayanan $\mathrm{KB}$ pria yang dinilai masih rendah.
Ciptaan disebarluaskan di bawah

Lisensi Creative Commons Atribusi-NonKomersialBerbagiSerupa 4.0 Internasional.

Salah satu faktor penting dalam membentuk prilaku adalah sikap atau persepsi. Seorang pasangan dengan persepsi positif terhadap alat kontrasepsi maka akan sebanding dengan penggunaan alat kontrasepsi, dibandingkan dengan suami yang berpersepsi negative terhadap alat kontrasepsi atau KB(Purwanti et al, 2014). Menurut Berkowitz (1972) dalam Azwar sikap adalah suatu reaksi perasaan yang muncul terhadap sesuatu. Sikap seseorang terhadap suatu objek adalah perasaan mendukung atau memihak (favorable) maupun perasaan tidak mendukung atau memihak (unfavorable) pada objek tersebut (Azwar, 2009).

Allport (1954) dalam Notoatmodjo (2014) juga memaparkan bahwa sikap itu mempunyai 3 unsur pokok, antara lain kepercayaan, kehidupan emosional dan kecondongan atau keinginan untuk bertindak. Sikap yang utuh dapat dibentuk secara bersama-sama oleh ketiga unsur ini, dan dapat diukur secara langsung maupun tidak langsung melalui pertanyaan, bagaimana pendapat atau pernyataan responden terhadap suatu objek (Notoatmodjo, 2014).

Berdasarkan hasil penelitian yang dilakukan (Barus et al, 2018) tentang hubungan pengetahuan, sikap dan pelayanan 
JURNAL ILMU KESEHATAN BHAKTI HUSADA:

HeAlth SCIENCES JOURNAL, Vol. 11 No. 02, DeSEMBER 2020 DOI: $10.34305 / j i k b h . v 11 i 2.169$
Ciptaan disebarluaskan di bawah

Lisensi Creative Commons

Atribusi-NonKomersial-

BerbagiSerupa 4.0 Internasional

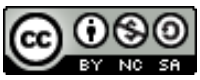

KB dengan keikutsertaan suami dalam menggunakan $\mathrm{KB}$, mengatakan bahwa pengetahuan yang baik, sikap yang positif serta pelayanan KB yang baik diberikan petugas kesehatan mempunyai pengaruh yang signifikan dengan keputusan pria untuk ikut serta dalam menggunakan kontrasepsi di Kecamatan Panguruan. Menurut penelitian (Winda, 2017) juga menunjukkan adanya hubungan yang signifikan antara pengetahuan tentang alat kontrasepsi pria dengan partisipasi dalam menggunakan kondom dan MOP di UPTD Puskesmas Ahuhu Kabupaten Konawe tahun 2017.

Hasil studi pendahuluan di Dinas Pengendalian Penduduk dan Keluarga Berencana (DPPKB) Kota Cirebon Kelurahan Kebonbaru pada bulan Juni 2019 jumlah Pasangan Usia Subur (PUS) adalah 1.022 jiwa dengan jumlah pria yang ikut berKB MOP 0 jiwa dan Kondom 4 jiwa. Berdasarkan data tersebut mengindikasikan bahwa cakupan peserta KB pria di Kelurahan Kebonbaru masih sangat rendah yaitu $0,39 \% \quad$ (DPPKB, 2019).Hal ini memberi dampak negatif bagi kaum wanita karena kesehatan reproduksi tidak hanya kaum wanita saja yang harus berperan aktif, melainkan kaum pria juga mempunyai tanggung jawab yang sama (BKKBN, 2016). Setelah dilakukan studi pendahuluan di
Kelurahan Kebonbaru Kota Cirebon menggunakan kuesioner dari 15 suami Pasangan Usia Subur (PUS) $20 \%$ suami mengetahui pengetahuan baik dan sikap positif dengan kontrasepsi pria, sedangkan $80 \%$ suami berpengetahuan kurang dan sikap negatif dengan kontrasepsi pria.

Berdasarkan latar belakang masalah tersebut penulis ingin melakukan penelitian mengenai "Hubungan Sikap Tentang Kontrasepsi Pria dengan Partisipasi Suami dalam Menggunakan Alat Kontrasepsi di Kelurahan Kebonbaru Kota Cirebon".

\section{Metode}

Jenis penelitian yang digunakan dalam penelitian ini adalah penelitian analitik dengan pendekatan cross sectional untuk memperoleh data yang lebih lengkap yang dilakukan dengan cepat dan sekaligus (Arikunto, 2014). Populasi pada penelitian ini adalah suami yang termasuk Pasangan Usia Subur (PUS) di Kelurahan Kebonbaru periode Juni sampai November 2019 berjumlah 1.022 jiwa, dengan jumlah sampel sebanyak 88 orang. Analisis yang dilakukan untuk menguji hubungan antara masingmasing variabel bebas dan variabel terikat dilakukan uji statistik chi-kuadrat dengan tujuan untuk melihat apakah hubungan yang terjadi memang bermakna secara statistik 
JURNAL ILMU KESEHATAN BHAKTI HUSADA:

HEALTH SCIENCES JOURNAL, VOL. 11 No. 02, DESEMBER 2020

DOI: $10.34305 / j i k b h . v 11 i 2.169$

atau hanya secara kebetulan (Arikunto, 2014).

\section{Hasil Penelitian}

Tabel 1 Distribusi Frekuensi Pendidikan Responden

\begin{tabular}{ccc}
\hline Kejadian Anemia & Frekuensi (f) & Prosentase (\%) \\
\hline Pendidikan Tinggi & 7 & $8.0 \%$ \\
$\begin{array}{c}\text { Pendidikan Menengah } \\
\text { Tidak Sekolah dan Sekolah } \\
\text { Dasar }\end{array}$ & 75 & $85.2 \%$ \\
\hline Jumlah & 6 & $6.8 \%$ \\
\hline
\end{tabular}

Berdasarkan tabel distribusi frekuensi diatas dapat dilihat bahwa sebanyak 75 responden $(85.2 \%)$ telah menempuh pendidikan sampai dengan tingkat menengah.

Tabel 2. Distribusi Frekuensi Pekerjaan Responden

\begin{tabular}{ccr}
\hline Pekerjaan & Frekuensi (f) & Prosentase (\%) \\
\hline Bekerja & 87 & $98.9 \%$ \\
Tidak Bekerja & 1 & $1 \%$ \\
\hline Jumlah & $\mathbf{8 8}$ & $\mathbf{1 0 0} \%$ \\
\hline
\end{tabular}

Berdasarkan tabel distribusi frekuensi diatas dapat dilihat bahwa sebanyak 87 responden $(98.9 \%)$ telah bekerja.

Tabel 3. Distribusi Frekuensi Sikap Tentang Kontrasepsi Pria

\begin{tabular}{ccc}
\hline Sikap & Frekuensi (f) & Prosentase (\%) \\
\hline Positif & 35 & $39.8 \%$ \\
Negatif & 53 & $60.2 \%$ \\
\hline Jumlah & $\mathbf{8 8}$ & $\mathbf{1 0 0} \%$ \\
\hline
\end{tabular}

Berdasarkan tabel distribusi frekuensi diatas dapat dilihat bahwa sebanyak 53 responden $(60,2 \%)$ berada pada kelompok sikap dengan kategori negatif.

Tabel 4. Distribusi Frekuensi Partisipasi Responden

\begin{tabular}{lll}
\hline Partisipasi & Frekuensi (f) & Prosentase (\%) \\
\hline
\end{tabular}


JURNAL ILMU KESEHATAN BHAKTI HUSADA:

HEALTH SCIENCES JOURNAL, VOL. 11 No. 02, DESEMBER 2020

DOI: $10.34305 / j i k b h . v 11 i 2.169$
Ciptaan disebarluaskan di bawah

Lisensi Creative Commons

Atribusi-NonKomersial-

BerbagiSerupa 4.0 Internasional.

\begin{tabular}{ccc}
\hline Ya & 10 & $11.4 \%$ \\
Tidak & 78 & $88.6 \%$ \\
\hline Jumlah & $\mathbf{8 8}$ & $\mathbf{1 0 0 \%}$ \\
\hline
\end{tabular}

Berdasarkan tabel distribusi frekuensi diatas dapat dilihat bahwa sebanyak 78 responden $(88,6 \%)$ tidak ikut berpartisipasi dalam penggunaan kontrasepsi pria.

Tabel 5. Tabulasi Silang antara Sikap dan Partisipasi Responden

\begin{tabular}{|c|c|c|c|c|c|}
\hline & & \multicolumn{2}{|c|}{ Partisipasi } & \multirow{2}{*}{ Total } & \multirow{2}{*}{ P Value } \\
\hline & & $\mathrm{Ya}$ & Tidak & & \\
\hline \multirow{2}{*}{ Sikap } & Positif & 10 & 25 & 35 & \multirow{3}{*}{0,001} \\
\hline & Negatif & 0 & 53 & 53 & \\
\hline \multicolumn{2}{|c|}{ Total } & 10 & 78 & 88 & \\
\hline
\end{tabular}

Berdasarkan hasil analisa bivariate dengan menggunakan analisis Chi-square, didapatkan nilai $p$ value sebesar 0,001 lebih kecil dari nilai alpha 0,05, maka H0 ditolak sehingga dapat disimpulkan ada hubungan antara sikap tentang kontrasepsi pria dengan partisipasi suami menggunakan alat kontrasepsi di Kelurahan Kebonbaru Kota Cirebon.

\section{Pembahasan}

Berdasarkan hasil analisa bivariate dengan menggunakan analisis Chi-square ada tabel di atas, didapatkan nilai $p$ value sebesar 0,001 lebih kecil dari nilai alpha 0,05, maka H0 ditolak sehingga dapat disimpulkan ada hubungan antara sikap tentang kontrasepsi pria dengan partisipasi suami dalam menggunakan alat kontrasepsi di Kelurahan Kebonbaru Cirebon.

Salah satu faktor penting dalam membentuk prilaku adalah sikap atau persepsi. Seorang pasangan dengan persepsi positif terhadap alat kontrasepsi maka akan sebanding dengan penggunaan alat kontrasepsi, dibandingkan dengan suami yang berpersepsi negative terhadap alat kontrasepsi atau KB(Purwanti et al, 2014). Menurut Berkowitz (1972) dalam Azwar sikap adalah suatu reaksi perasaan yang muncul terhadap sesuatu. Sikap dapat dijabarkan sebagai reaksi tertutup dari seseorang terhadap suatu suatu objek atau rangsangan. Sikap dinilai belum merupakan suatu predisposisi dari prilaku seseorang. Dari beberapa pemaparan tersebut diatas dapat disimpulkan bahwa sikap itu tidak dapat langsung dilihat oleh seseorang, tetapi 
JURNAL ILMU KESEHATAN BHAKTI HUSADA:

HeAlth SCIENCES JOURNAL, Vol. 11 No. 02, DeSEMBER 2020 DOI: $10.34305 / j i k b h . v 11 i 2.169$

hanya dapat ditafsirkan dari prilaku yang tertutup terlebih dahulu (Notoatmodjo, 2014).

Sebagai suatu respon evaluatif, sikap akan muncul apabila seseorang mendapatkan stimulus atau dihadapkan pada suatu rangsangan yang menimbulkan adanya reaksi individu. Respon evaluatif ini menjelaskan bahwa reaksi yang muncul dinyatakan sebagai sikap yang timbul akibat adanya respon proses evaluasi dalam diri seseorang yang memberikan kesimpulan terhadap rangsangan dalam bentuk penilaian berupa positif atau negatif, baik atau buruk, dan sebagainya, yang kemudian ditunjukkan sebagai sikap. Rendahnya partisipasi suami dapat dimungkinkan oleh sikap suami yang tidak mendukung terhadap program keluarga berencana, karena kemungkinan rendahnya pengetahuan dari suami terhadap program KB, terutama belum begitu paham dengan metode kontrasepsi vasektomi, bagaimana keuntungan dan kerugiannya (Rizkia Isnani H, 2017).

Dari hasil tabulasi silang dapat dilihat bahwa responden dengan sikap yang negatif tidak ikut berpartisipasi dalam penggunaan alat kontrasepsi pria. Hal ini sejalan dengan penelitian (Tourisia et al, 2015) dengan hasil uji korelasi spermank rank diperoleh koefisien korelasi sebesar
Ciptaan disebarluaskan di bawah

Lisensi Creative Commons Atribusi-NonKomersialBerbagiSerupa 4.0 Internasional
0,381 dengan $p$ value sebesar 0,000 . Oleh karena itu $\mathrm{Z}$ hitung lebih besar dari $\mathrm{Z}$ tabel dan $p$ value $<0,05$, maka Ho ditolak. Artinya ada hubungan yang signifikan antara sikap suami dengan partisipasi suami dalam menggunakan alat kontrasepsi.

Menurut penelitian (Barus et al, 2018), menunjukkan bahwa terdapat hubungan antara sikap suami dengan keikutsertaan menggunakan alat kontrasepsi di Kecamatan Pangururan, sikap mempunyai hubungan yang erat untuk mengaplikasikan terjadinya suatu perilaku dari individu. Sikap seseorang dipengaruhi pula oleh aspek pengetahuan yang berisikan aspek positif dan negatif dari suatu objek. Apabila seseorang menilai bahwa program $\mathrm{KB}$ mempunyai lebih banyak aspek positif, maka aspek positif itu lebih dinilai penting dari aspek negatif, sehingga akan akan menubuhkan perilaku atau sikap yang positif juga, sebaliknya pun demikian.

Dari hasil penelitian dapat diketahui bahwa 39,8\% memiliki sikap positif dan $60,2 \%$ memiliki sikap yang negatif, hal ini dapat dimungkinkan dari kurangnya pengetahuan responden terhadap alat kontrasepsi pria, mereka lebih memilih agar istrinya yang ikut $\mathrm{KB}$ dibandingkan dengan suami, dan tugas suami yang utama adalah mencari nafkah sehingga beban untuk ber 
JURNAL ILMU KESEHATAN BHAKTI HUSADA:

HeAlth SCIENCES JOURNAL, Vol. 11 No. 02, DeSEMBER 2020 DOI: $10.34305 / j i k b h . v 11 i 2.169$
Ciptaan disebarluaskan di bawah

Lisensi Creative Commons

Atribusi-NonKomersial-

BerbagiSerupa 4.0 Internasional.
$\mathrm{KB}$ atau pun mengurus rumah tangga dilimpahkan kepada istri. Sebagian besar responden bekerja sebagai pedagang.Dari analisis hasil penelitian tersebut juga dapat dilihat sebagian besar pendidikan responden adalah menengah, bahkan ada juga yang masih rendah, sehingga dimungkinkan tingkat pengetahuan atau akses informasi yang diserap oleh responden kurang, sehingga menimbulkan tumbuhnya sikap negatif dari responden untuk ikut berpartisipasi dalam program ini. Responden diharapkan dapat meningkatkan pengetahuan baik secara langsung ataupun tidak, sehingga dapat meningkatkan cakupan dalam penggunaan alat kontrasepsi, sehingga dapat membantu keluarga dalam hal ini istrinya dalam mengatur jarak kehamilan dan persalinan, bahkan secara tidak langsung membantu pemerintah dalam menekan angka ledakan penduduk.

Dari hasil penelitian di atas dapat dilihat hanya 10 orang yang ikut berpartisipasi dalam penggunaan kontrasepsi pria dan sebanyak 78 orang tidak ikut berpartisipasi. Dari 10 orang 1 orang telah menggunakan MOP dan 9 orang lainnya menggunakan kondom.

Kontrasepsi merupakan suatu upaya yang bersifat sementara ataupun permanen untuk dapat mencegah terjadinya kehamilan, atau mengatur jarak kehamilan (Prawiroharjo, 2013). Salah satu jenis kontrasepsi pria adalah kondom, yaitu suatu alat kontrasepsi yang terbuat dari lateks berupa sarung yang diselubungkan ke alat reproduksi pria (penis). Kondom ini mencegah pertemuan antara sperma dengan sel telur sehingga tidak terjadi fertilisasi, selain itu kondom juga dapat melindungi dari paparan infeksi menular seksual (IMS) (Meilani, Setyawati, Estiwidani, \& Suherni, 2010).

Kondom dinilai cukup efektif mencegah terjadinya kehamilan apabila dipakai secara benar setiap kali melakukan hubungan seksual/coitus. Secara ilmiah didapatkan hanya sedikit angka kegagalan kondom yaitu 2-12 kehamilan per 100 wanita per tahun. Selain penggunaan kondom alat kontrasepsi bagi pria secara mantap atau permanen juga ada yaitu vasektomi. Vasektomi adalah kontrasepsi mantap dimana dilakukan operasi kecil, vas deferens yang berfungsi sebagai saluran spermatozoa dipotong dan disumbat. Setelah operasi kecil ini dilakukan akan memberikan efek terbendungnya spermatozoa pada ujung vas sisi testis yang telah disumbat. Walaupun telah dilakukan pemotongan pada saluran spermatozoa/ vas deferens, vasektomi tidak mempengaruhi fungsi dari 
JURNAL ILMU KESEHATAN BHAKTI HUSADA:

HeAlth SCIENCES JOURNAL, Vol. 11 No. 02, DeSEMBER 2020 DOI: $10.34305 / j i k b h . v 11 i 2.169$
Ciptaan disebarluaskan di bawah

Lisensi Creative Commons Atribusi-NonKomersialBerbagiSerupa 4.0 Internasional.

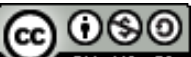

kelenjar-kelenjar asesoris maka produksi cairan semen tetap berlangsung dan tetap dapat berejakulasi tanpa mengandung sel spermatozoa. Testis juga tidak terpengaruh dan tetap berfungsi sebagaimana fungsinya sehingga laki-laki tetap mempunyai hasrat untuk berhubungan seksual yang sama seperti sebelum dilakukannya vasektomi (Setiyaningrum, 2015). Namun sangat sedikit sekali para pria yang memilih ikut berpartisipasi dengan metode ini, karena kebanyakan dari mereka khawatir dengan efek samping yang akan terjadi, dan takut terhadap proses pembedahan yang dilakukan.

Senggama terputus juga merupakan salah satu cara kontrasepsi pria, yaitu alat kelamin pria (penis) dikeluarkan sebelum ejakulasi sehingga sperma tidak masuk ke dalam vagina dan kehamilan dapat dicegah, cara ini tidak berbahaya baik fisik maupun mental, kepuasan terpelihara pada kedua belah pihak, terlebih-lebih apabila ada saling pengertian yang baik di antara mereka (Meilani et al., 2010), namun penggunaan metode ini sangat rentan gagal, dan responden tidak menginginkan metode ini karena dianggap mengganggu kenikmatan hubungan seksual. Efektivitas bergantung pada kesediaan pasangan untuk melalukan koitus terputus setiap melaksanakannya (angka kegagalan 4-18 kehamilan per 100 perempuan per tahun). Sehingga diharapkan pihak puskesmas dapat mensosialisasikan keuntungan dari berbagai macam $\mathrm{KB}$, dan sasaran untuk kegiatan penyuluhan atau sosialisasi sebaiknya bukan hanya pada WUS, tetapi PUS, sehingga peran aktif dari para suami dapat lebih ditingkatkan dalam program Keluarga Berencana ini.

\section{Kesimpulan}

Dari hasil penelitian tentang hubungan sikap tentang kontrasepsi pria dengan partisipasi suami dalam menggunakan alat kontrasepsi di Kelurahan Kebonbaru Kota Cirebon, dapat disimpulkan terdapat hubungan sikap tentang kontrasepsi pria dengan partisipasi suami dalam menggunakan alat kontrasepsi di Kelurahan Kebonbaru Kota Cirebon dengan nilai $p$ value sebesar 0,001 lebih kecil dari nilai alpha 0,05 .

\section{Saran}

Diharapkan bagi pria Pasangan Usia Subur (PUS) dapat meningkatkan pengetahuan melalui informasi secara langsung dari petugas kesehatan atau media social sehingga dapat meningkatkan pengetahuan seputar alat kontrasepsi agar suami dapat ikut serta berpartisipasi dalam 
JURNAL ILMU KESEHATAN BHAKTI HUSADA:

HEALTH SCIENCES JOURNAL, VOL. 11 No. 02, DESEMBER 2020 DOI: $10.34305 / j i k b h . v 11 i 2.169$

penggunaan alat kontrasepsi. Petugas kesehatan juga diharapkan dapat secara tepat menyampaikan informasi pada akseptor KB, bukan hanya wanita tetapi diharapkan juga pria atau suami dapat menerima informasi tersebut, sehingga dapat membantu mensukseskan program KB dalam mencegah ledakan penduduk.

\section{Daftar Pustaka}

Azwar. (2009). Sikap Manusia dan Teori Pengukurannya. Jogjakarta: Pustaka Pelajar.

Barus, E., Lumbantoruan, M., Erna, A., \& Purba, T. (2018). Hubungan pengetahuan, sikap dan pelayanan KB dengan keikutsertaan pria mengikuti KB The relationship of knowledge , attitude and family planning services with the participation of men following KB. Jurnal Health of Studies, Vol 3, No, 36-46.

BKKBN. (2016). Laporan dan Cakupan Pelayanan Keluarga Berencana.

BPS. (2018). Statistik Indonesia 2018. (c), 2-6.

Departemen Kesehatan. (2014). Pusat data dan Informasi Kesehatan. Jakarta.

DPPKB. (2019). Laporan Bulanan PUS dan Jumlah Peserta KB Kota Cirebon 2019. Cirebon.

Ika. (2009). KB Wujudkan Keluarga Berkualitas. Retrieved from https://ugm.ac.id/id/berita/1293-kb-
Ciptaan disebarluaskan di bawah

Lisensi Creative Commons

Atribusi-NonKomersial-

BerbagiSerupa 4.0 Internasional.

wujudkan-keluarga-berkualitas

Kemenkes RI. (2018). Profil Kesehatan Indonesia Tahun 2017. In Ministry of Health Indonesia. Jakarta.

Meilani, N., Setyawati, N., Estiwidani, D., \& Suherni. (2010). Pelayanan Keluarga Berencana. Retrieved from fitramaya@yahoo.com

Notoatmodjo, S. (2014). Ilmu Prilaku Kesehatan. Jakarta: Rineka Cipta.

Novianti, S. dan R. (2014). Faktor Presepsi dan Dukungan Istri yang Berhubungan dengan Partisipasi KB Pria. Jurnal Kesehatan Komunitas Indonesia.

Prawiroharjo, S. (2013). Pelayanan Kesehatan Maternal dan Neonatal. In Pelayanan Kesehatan Materanal dan Neonatal.

Purwanti, E, Moloku, M, Hutagaol, E. (2014). Hubungan Sikap dengan Motivasi Menjadi Akseptor KB Pria di Puskesmas Siborong-Borong. Reproductive Health.

Purwoastuti. (2014). Kesehatan Reproduksi dan Keluarga Berencana. Jogjakarta: Pustaka Baru Press.

Rizkia Isnani H. (2017). Hubungan Pengetahuan dan Sikap Terhadap Pengguna Alat Kontrasepsi Vasektomi di Kelurahan Bakung Loa Kota Samarinda.

Saputri, Winda, Y. (2017). Hubungan Pengetahuan Tentang Kontrasepsi Pria Dengan Partisipasi Pria Dalam Menggunakan Kondom dan MOP di UPTD Puskesmas Ahuhu Kabupaten Konawe Tahun 2017. 
JURNAL ILMU KESEHATAN BHAKTI HUSADA:

HEALTH SCIENCES JOURNAL, VOL. 11 No. 02, DESEMBER 2020

DOI: $10.34305 / j i k b h . v 11 i 2.169$
Ciptaan disebarluaskan di bawah

$\underline{\text { Lisensi Creative Commons }}$ Atribusi-NonKomersialBerbagiSerupa 4.0 Internasional.

Setiyaningrum, E. (2015). Pelayanan Keluarga Berencana \& Kesehatan Reproduksi. Trans Info Media.

Suharsimi Arikunto. (2014). Prosedur Penelitian Suatu Pendekatan Praktik (Cet. 15). Jakarta: Rineka Cipta.

Tourisia, D., Sumarah, \& Hartini. (2015). Hubungan Pengetahuan Dan Sikap Dengan Partisipasi Suami Dalam Ber Kb. Jurnal Involunsi Kebidanan, 5(9), 50-64.

World Population Data Sheet. (2019). Family Planning Data Sheet 2019. 